\title{
RETABLISTICA NOVOHISPANA EN EL ESTADO DE HIDALGO
}

JosÉ GuADALUPE VicTORIA

La historiografía acerca del arte hispanoamericano reconoce como dos piedras de toque la originalidad y la singularidad de las expresiones artísticas surgidas de este lado del Atlántico. No es, ni con mucho, este el lugar para insistir en una discusión que quizá cae por su propio peso. Pero si hemos querido apuntarla es porque ella misma no ha impedido que los principales historiadores de dicho arte reconozcan que varias de las expresiones artísticas de los otrora virreinatos americanos se cuentan entre las creaciones más originales del arte occidental. Una de esas'expresiones la constituyen los retablos, así lo reconoce Damián Bayón, quien dice: "en nuestros estilos coloniales la mayor originalidad se encuentra, casualmente, para mí, a nivel de los retablos, gran invención plástico-religiosa de la Península Ibérica y sus prolongaciones americanas".

Así, pues, aunque las raíces de dicha expresión artística se encuentran en la Península, su desarrollo en nuestro continente tuvo particularidades que poco a poco - a medida que los estudios de historia del arte avanzan - se van perfilando. Por eso no resulta extraño hablar de "escuelas" y "estilos" regionales tanto en América del Sur como en México, Centroamérica y el Caribe. $Y$ aún dentro de estas áreas geográficas se nota gran variedad en las obras de una región o, incluso, dentro de una misma ciudad y en el mismo período; sobre todo en la época barroca. A nadie escapa, por ejemplo, la diferencia que existe entre la retablística brasileira, la del virreinato peruano y la de Nueva España. ${ }^{2}$

Ahora bien, por lo que se refiere a esta última, podemos decir que su estudio aún es muy incompleto, pese a los esfuerzos generales y particulares de varios estudiosos nacionales y extranjeros. ${ }^{3} \mathrm{El}$ enfoque de dichos

1 Damián Bayón. Texto en la tevista Plural.

${ }^{2} \mathrm{El}$ primer estudio acerca de los retablos de la Nueva España fue realizado por Getardo Murillo (Dr. Atl), quien lo incluyó en el volumen $\mathrm{V}$ de la obra Iglesias de México, Altares, México, Publicaciones de la Secretaría de Hacienda, 1925, 94 p., ils. El segundo gran esfuerzo por mostrar el desarrollo de los retablos novohispanos se debe a Francisco de la Maza, Los retablos dorados de Nueva España, México, Ediciones Mexicanas, 1950, 43 p. Enciclopedia Mexicana de Atte. De entonces a la fecha los estudios sobre tetablos han continuado paulatinamente.

${ }^{3}$ Vid. José Guadalupe Victoria y María Teresa Velasco, Bibliografía de Arte Novobispano. 1521-1985. En prensa. 
estudios ha variado pero, en términos generales, puede agruparse de la siguiente manera: documental, iconográfico, de análisis formal y de filiación estilística. ${ }^{4}$

Sin embargo, creemos que faltan estudios básicos —más elementales, si se quiere- en los cuales se recupere la información esencial acerca de los retablos existentes en las diversas provincias de la antigua Nueva España para que, con base en ellos, puedan lograrse aproximaciones más profundas y adecuadas - más certeras, por qué no- acerca de distintos aspectos de dicha expresión plástica.

Con este empeño, hace algunos años emprendimos la realización de un Catálogo de Retablos Novohispanos en el Estado de Hidalgo, pues, pensábamos, a priori, que podía servir de base para un estudio mayor acerca de la creación artística virreinal en dicha entidad. Por razones que no es el caso mencionar aquí el trabajo no pudo concluirse y es solo de unos meses a la fecha que lo hemos retomado; naturalmente ha cambiado el sentido con que la investigación fue concebida en su origen. Si bien aprovechamos la información recabada a lo largo de varios años.

Como es del conocimiento general -y aunque parezca exagerado señalarlo- la aparición de los retablos en la Nueva España corrió pareja a la conquista material y espiritual. Tales retablos debieron tener cierto carácter efímero, e incluso se les podía transportar. En la medida en que los frailes se establecían, el carácter imperecedero de estas obras debió aumentar. Cuando la evangelización terminó, las diversas comunidades religiosas encargaron numerosos retablos.

En un primer momento parece ser que la falta de artistas españoles favoreció el desarrollo de la retablística entre los indígenas, quienes realizaron obras muy variadas. ${ }^{5}$ Pero cuando los religiosos se empeñaban en poseer obras de mayor envergadura, las hacían venir de España. Por ejemplo los dominicos trajeron el altar mayor para su iglesia de México. Según el testimonio de Dávila Padilla se encargaron todas las piezas del retabilo, salvo las pinturas que fueron encomendadas a un pintor local. ${ }^{6}$

Tales obras fueron reemplazadas por otras más suntuosas, a medida que los recursos económicos aumentaron. No obstante, existen testimonios documentales de la época que permiten formarse una idea de ellas. Esta

\footnotetext{
${ }^{4}$ Ibidem.

־ José Guadalupe Victoria, Pintura y Sociedad en Nueva España. Siglo XVI En prensa.

${ }^{6}$ Ftay Agustín Dávila Padilla, Historia de la Provincia de Santiago de México, pp. $580-581$.
} 


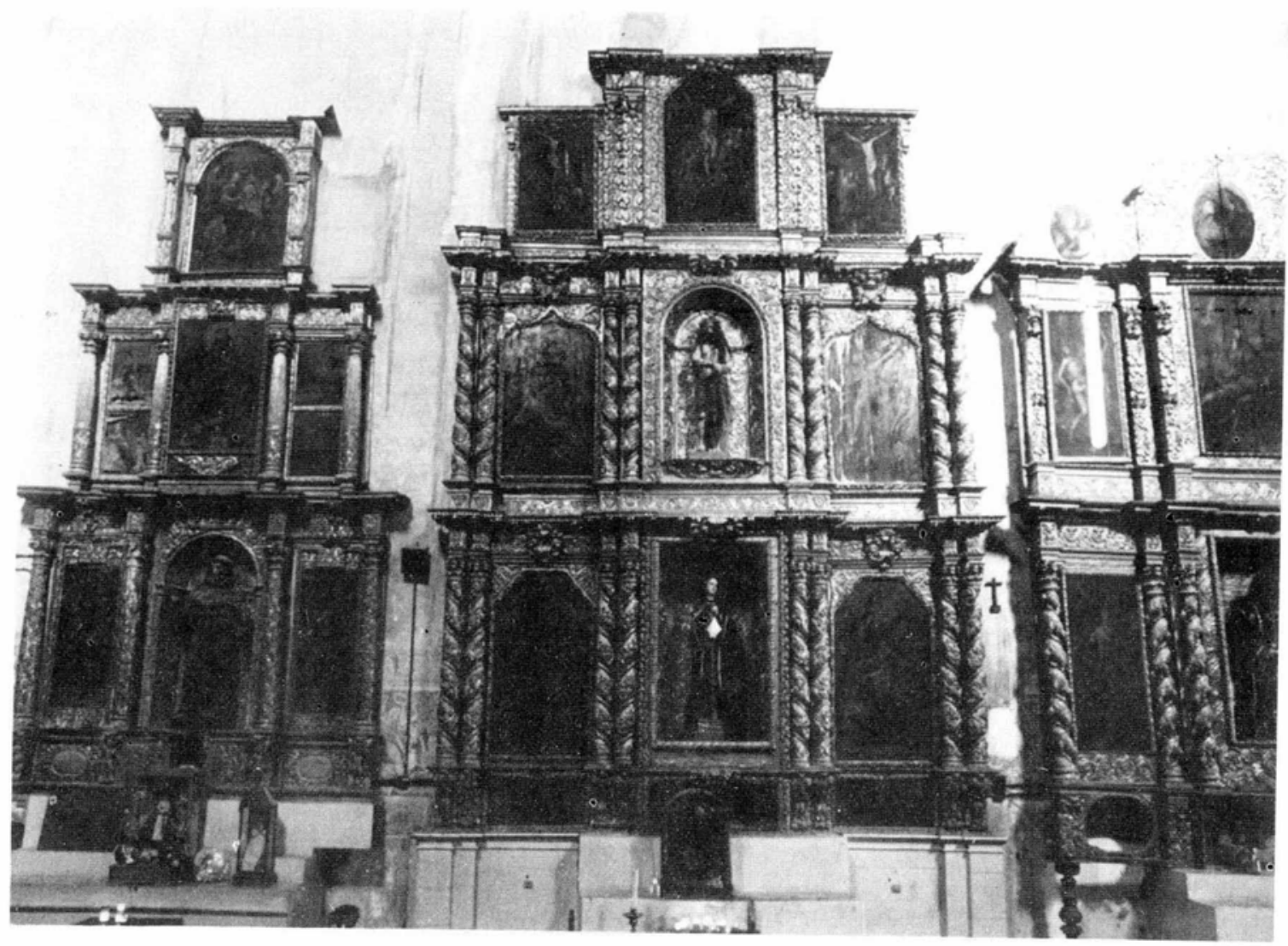

Figura 1. Retablos laterales de la iglesia de Los Santos Reyes Meztitlán. Foto: G.V.R. 


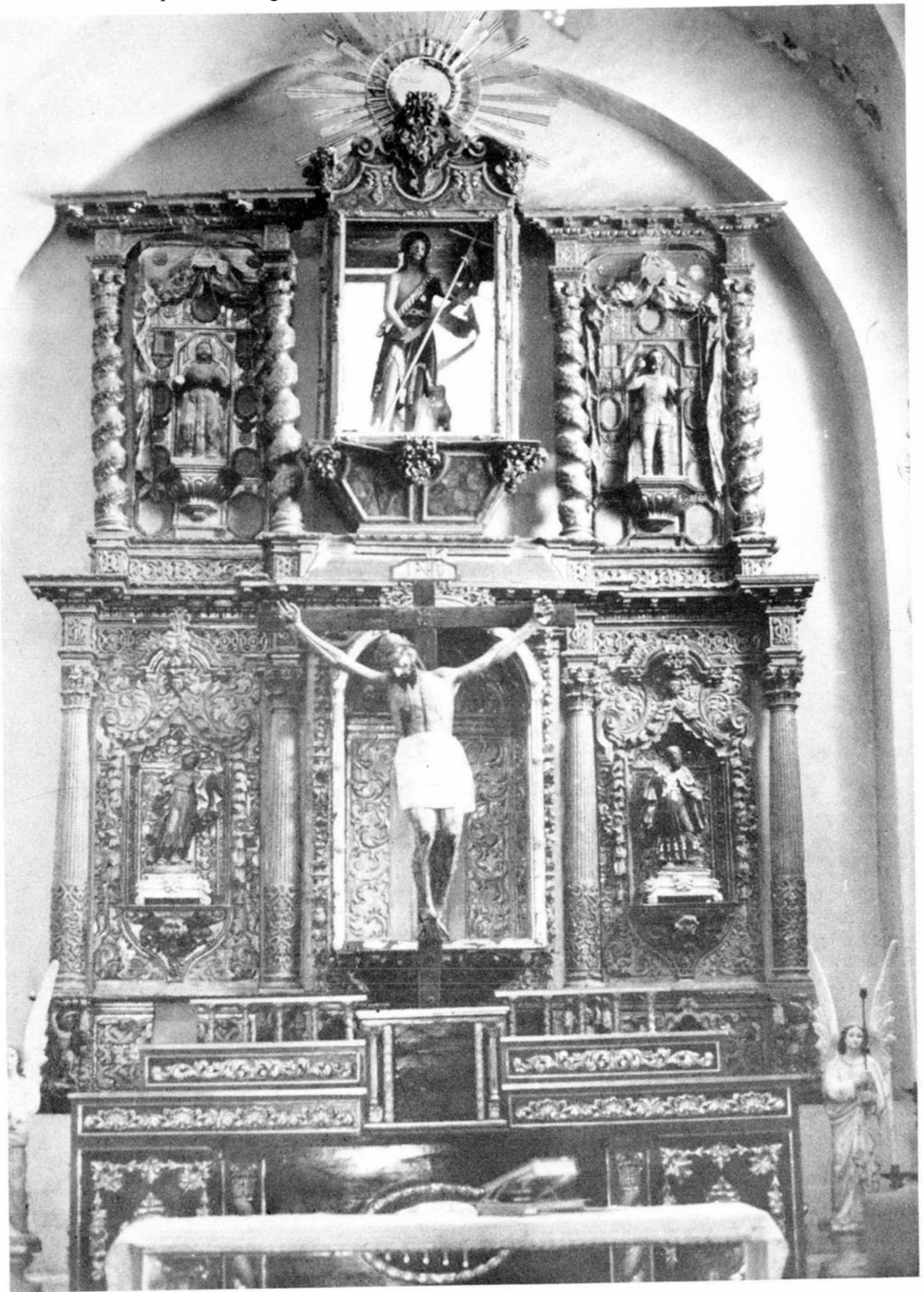

Figura 2. Retablo de la iglesia de Santa María Tolcayuca. Foto: J.G.V. 
DOI: http://dx.doi.org/10.22201/iie.18703062e.1986.57.1334

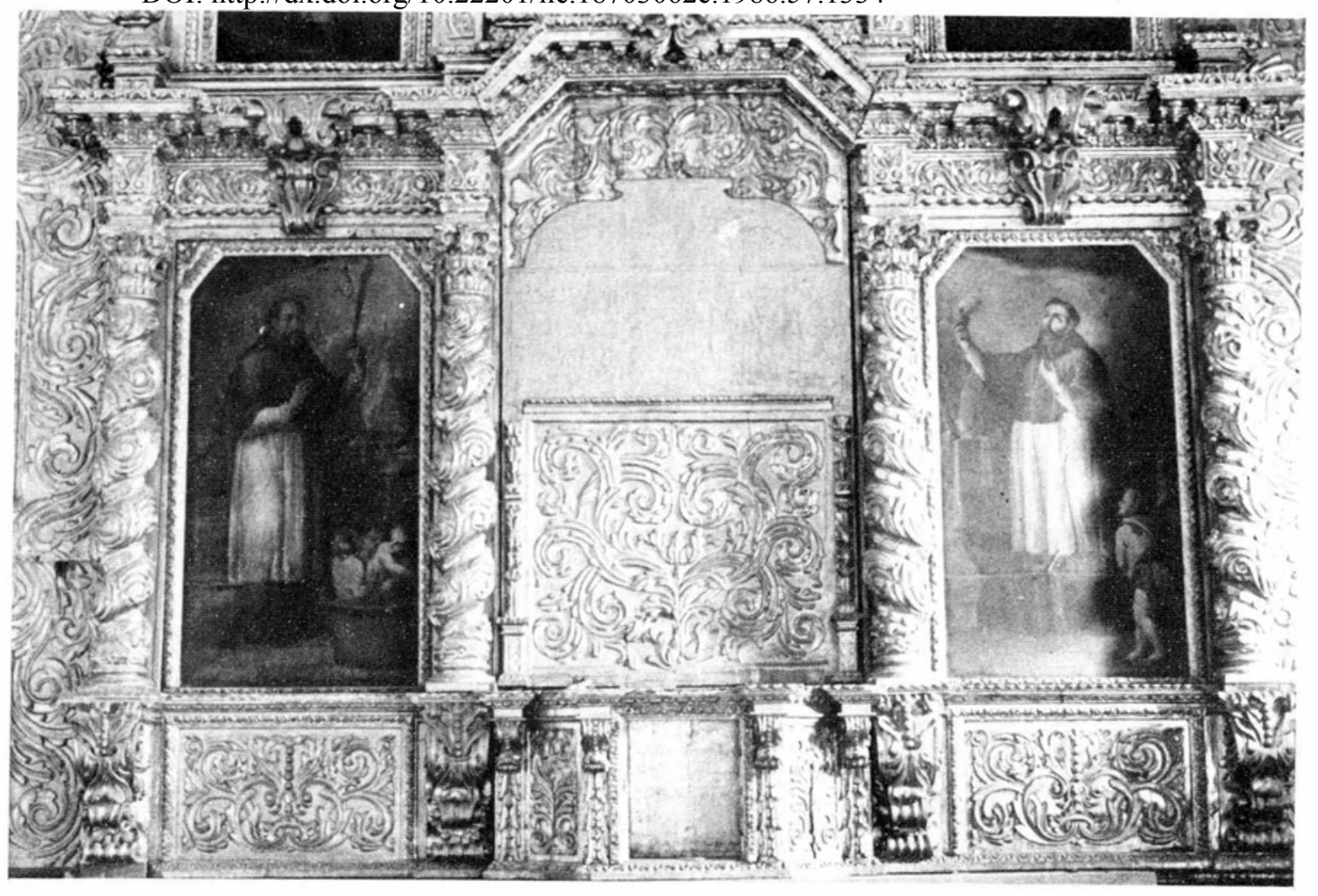

Figura 3. Retablo de Nuestra Señora de Guadalupe (detalle). Sanguilucan. Foto: J.G.V. 
DOI: http://dx.doi.org/10.22201/iie.18703062e.1986.57.1334

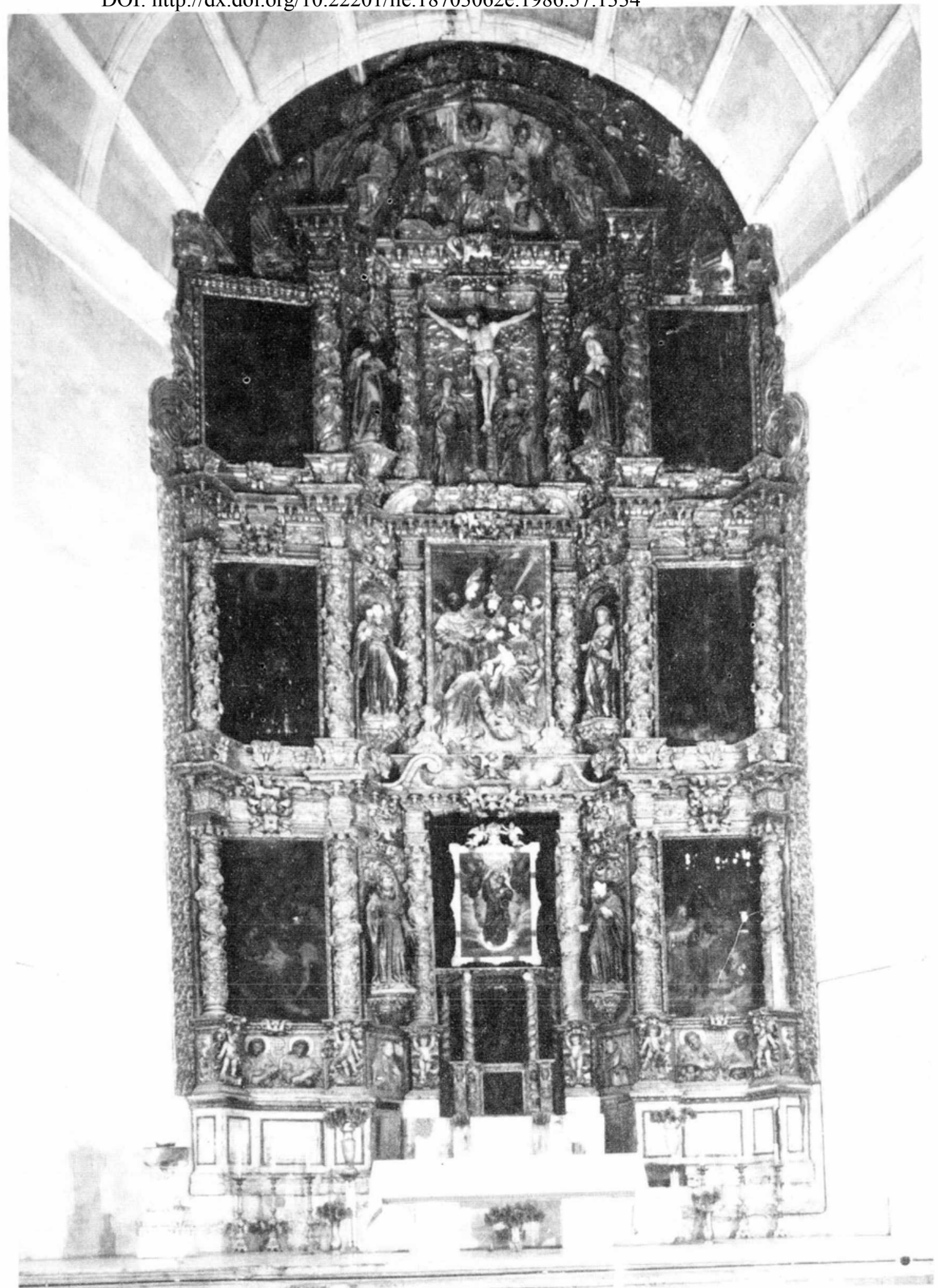

Figura 4. Retablo mayor de la iglesia de Los Santos Reyes Meztitlán. Foto: J.G.V. 


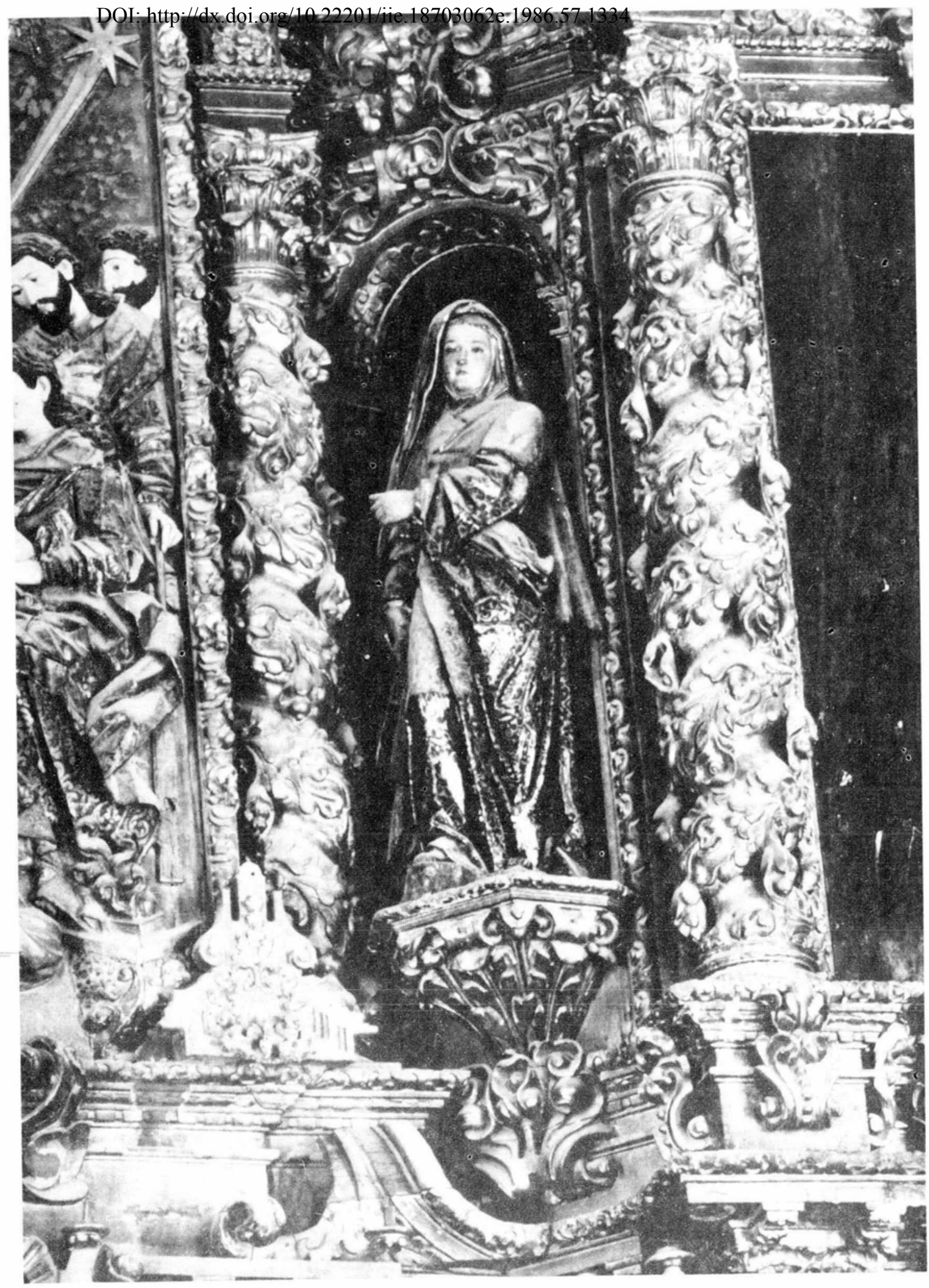

Figura 5. Retablo mayor de la iglesia de Los Santos Reyes Meztitlán (detalle). Foto: I.I.E. 


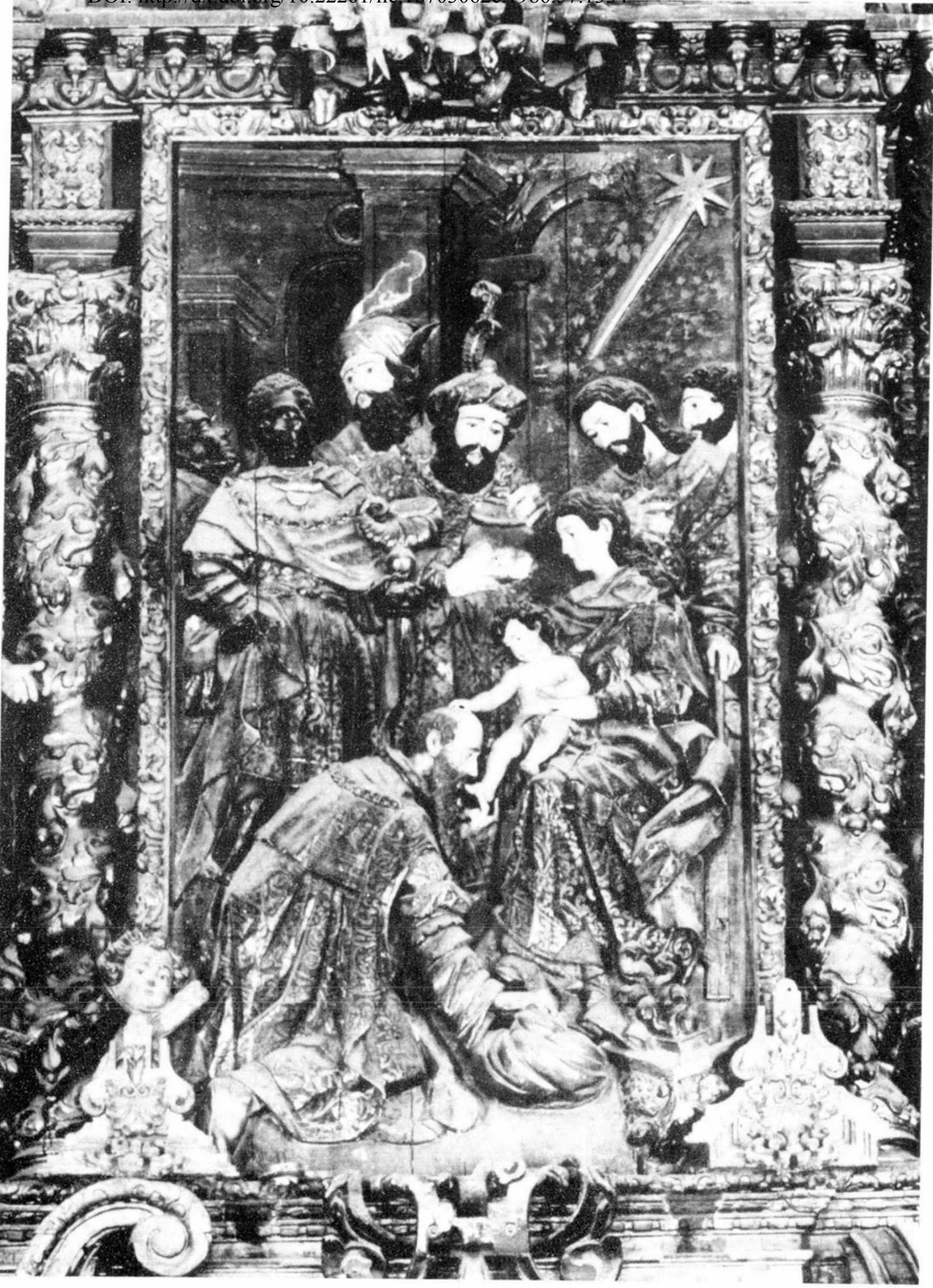

Figura 6. Retablo mayor de la iglesia de Los Santos Reyes Meztitlán (detalle). Foto: I.I.E. 


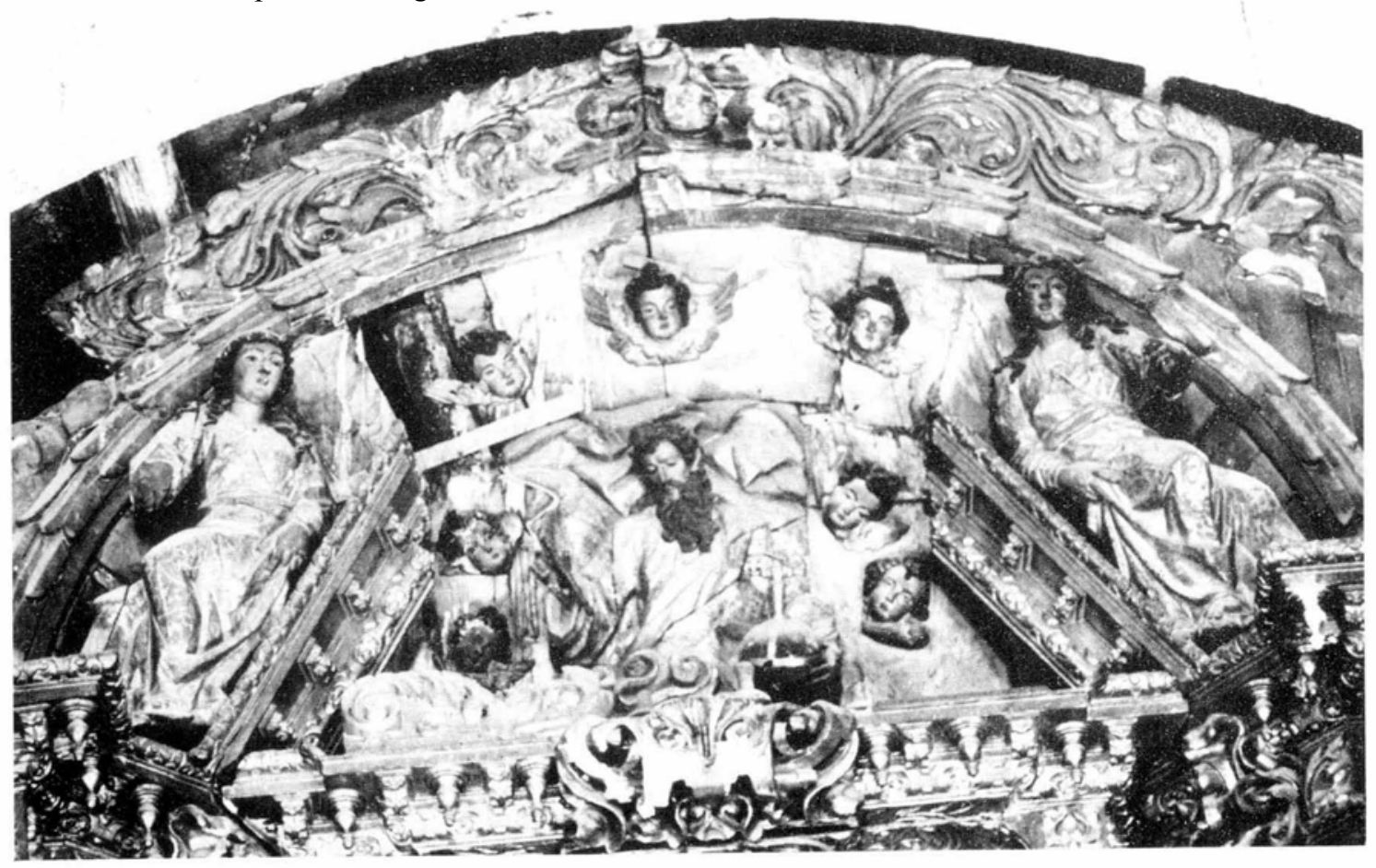

Figura 7. Retablo mayor de la iglesia de Los Santos Reyes Meztitlán (detalle). Foto: I.I.E. 
DOI: http://dx.doi.org/10.22201/iie.18703062e.1986.57.1334

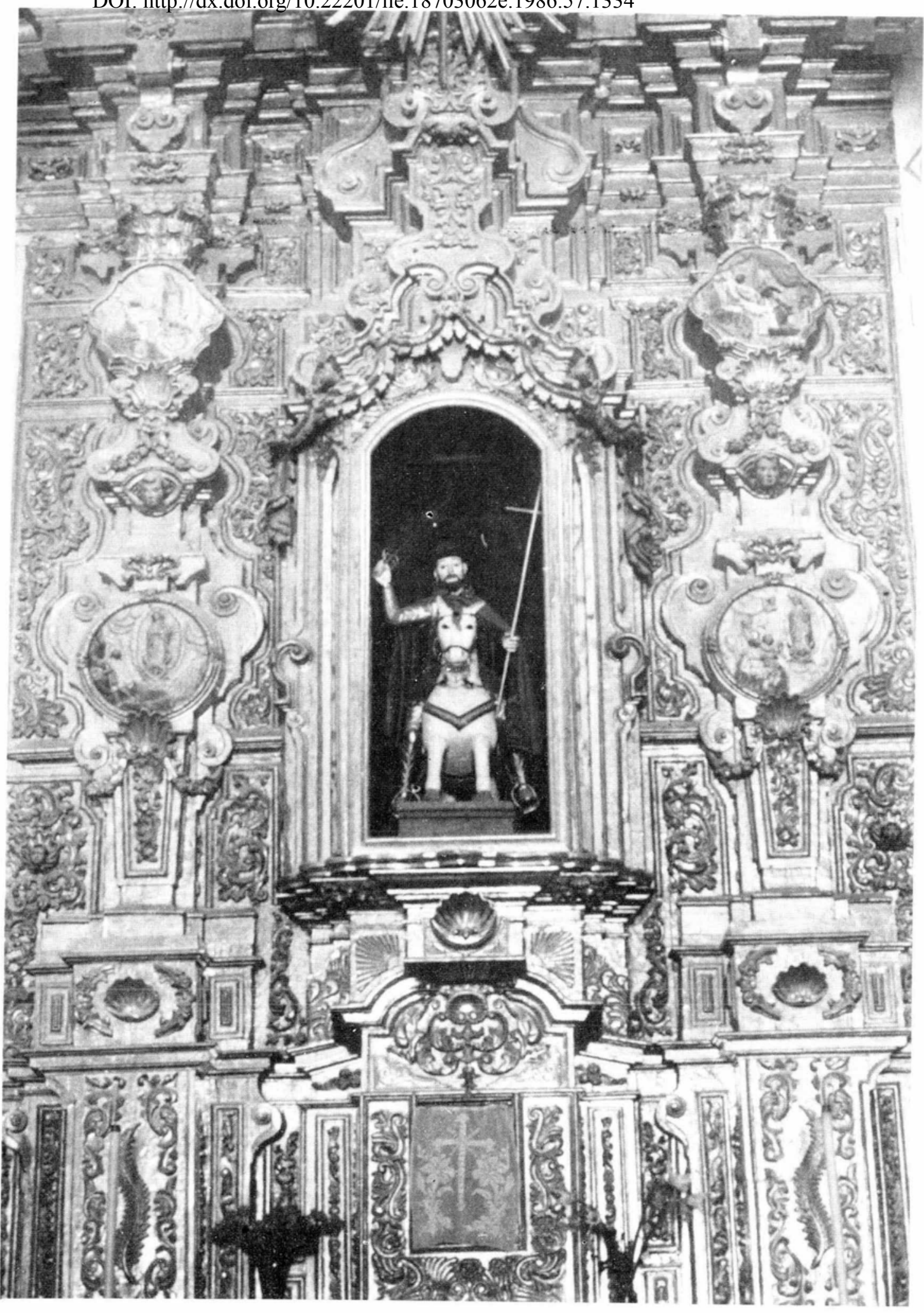

Figura 8. Retablo mayor de la iglesia de Atotonilco de Tula (detalle). Foto: J.G.V. 
información es importante pues permite estudiar otro aspecto del arte de la época: la iconografía. ${ }^{7}$

El período de mayor encargo de otras retablísticas, en el siglo XVI, coincide con la llegada de importantes artistas al virreinato: Simón Pereyns, Andrés de Concha, Francisco de Zumaya, Francisco de Morales y Baltasar de Echave Orio, entre otros. A ellos les tocó la realización de muchísimas obras y fueron ellos quienes iniciaron una tradición retablística de altos vuelos, la cual sirvió para el ulterior desarrollo del arte en tierras novohispanas. ${ }^{8}$

Por lo que se refiere a la retablística novohispana en el actual estado de Hidalgo, conviene advertir que no se conserva sino en mínima parte debido a la furia destructiva e ignorancia de propios y la no menor indiferencia de los extraños. ¿Cuántos retablos atesoraban las iglesias novohispanas del Estado de Hidalgo? Imposible saberlo. Los autores del benemérito Catálogo de Construcciones Religiosas del Estado de Hidalgo, ${ }^{9}$ publicado hace ya casi cincuenta años, registraron alrededor de cuarenta ejemplos. Por nuestra parte, al momento de iniciar nuestra investigación - 1978 - constatamos que tal cantidad había disminuído en un $20 \%$. Ojalá que propios y extraños tomemos conciencia de lo que implica la pérdida paulatina de tales obras artísticas.

La existencia de numerosos retablos en Hidalgo, durante la época colonial, queda confirmada por las informaciones documentales que por fortuna han aumentado en los últimos años; si bien la mayoría de estos informes se refieren a obras de los siglos XVII y XVIII. Pero no cabe duda que los grandes conjuntos conventuales del "siglo de oro de la iglesia mexicana" contaron con retablos que actualmente sólo podemos evocar con base en algunos fragmentos que andan dispersos en bodegas, fotografías antiguas y, sobre todo, por testimonios de los cronistas religiosios y documentos.

\section{Retablos del siglo XVI}

Aquí sólo habremos de referimos a cuatro retablos mayores -colaterales mayores, según la terminología de la época- que ornaban otras tantas iglesias: Epazoyucan, Meztitlán, Zempoala y Tula.

' José Guadalupe Victoria, op cit.

${ }^{8}$ Ibidem.

${ }^{9}$ Catálogo de construcciones religiosas del Estado de Hidalgo, introducción de Manuel Toussaint, recop de Justino Fernández, México, Sectetaría de Hacienda y Crédito Público, 1940, 2 vols. Hay una reimpresión hecha por el Gobietno del Estado de Hidalgo, en 1984 . 
Respecto al primero de ellos, su existencia queda probada por el testimonio del Arzobispo de México quien, en 1556, informaba al Consejo de Indias: "Hemos sabido que se hace un retablo para el Monasterio de Epazoyucan, que costará más de seis mil pesos". ${ }^{10}$ La fecha de esta información es muy temprana, por lo que suponemos que el retablo pudo cambiarse por otro en el mismo siglo XVI.

En cuanto al retablo de Meztitlán, tal como escribimos en otro lugar, ${ }^{11}$ su existencia queda probada por lo siguiente: en primer lugar se conserva una fotografía - publicada en el Catálogo ... - donde se ven dos columnas que sin duda alguna pertenecieron al antiguo retablo. En segundo lugar y confirmando la suposición anterior, está lo que en nuestro primer acercamiento a los retablos del conjunto mezca denominados retablo No. $4 .^{12}$ Se trata de un nicho flanqueado por columnas, sobre una predela y cargando un entablamento, que suponemos formaba parte del retablo original. En tercer lugar y último - también lo hemos asentado en otro artículo- ${ }^{13}$ una observación detallada del retablo mayor de esta iglesia, permite suponer que aloja varias esculturas que datan del siglo XVI.

Como se sabe, el convento franciscano de Zempoala empezó a construirse hacia 1570 y fue concluido quince años más tarde, es decir en $1585 .{ }^{14}$ En el coro de la iglesia se conserva, bastante maltrecho, un relieve que representa al Padre Eterno. Suponemos que esta pieza perteneció al antiguo retablo, el que tal vez fue realizado en la penúltima década del siglo XVI.

El retablo de Tula se sabe que fue realizado por Adrián Suster y Luis de Arciniega, éste último hermano del famoso arquitecto del mismo apellido. En dicha obra también participó otro célebre artista de la época: Simón Pereyns. ${ }^{1 *}$

10 Ibidem, v. I, p. 251.

11 José Guadalupe Victoria, Arte y Arquitectura en la Sierra Alta Siglo XVI, México, UNAM, Instituto de Investigaciones Estéticas, 1985. Cuadernos de historia del arte 24. i2 José Guadalupe Victoria. Monumentos Agustinos de la Sierra Alta. Siglo XVI. México, UNAM, Facultad de Filosofía y Letras, 1978. Tesis de Maestría en Historia de México.

13 José Guadalupe Victoria, "Forma y expresión en un retablo novohispano del siglo XVII". Estudios acerca del arte novohispano. Homenaje a Elisa Vargas Lugo, México, UNAM, Coordinación de Humanidades, 1983.

14 George Kubler, Arquitectura Mexicana del siglo XVI, México, Fondo de Cultura Económica, 1983, pp. 593-594.

${ }_{15}$ Manuel Toussaint, Arte Colonial en México, México, UNAM, Instituto de Investigaciones Estéticas, 1962, p. 65. 
Ahora bien, aunque carecemos de información precisa resulta evidente que esas cuatro obras fueron encargadas a artistas cuyos talleres estaban en la capital del virreinato.

\section{Retablos del siglo XVII}

En el estado actual de nuestra investigación, no podemos señalar cuántos retablos se conservan de esta centuria. Sin embargo, quedan en pie los de la iglesia de los Santos Reyes, en Meztitlán, y otros en Zimapan, Tolcayuca, Santa María Nativitas y Singuilucan, aquí hemos de referimos únicamente al retablo mayor de Meztitlán (figuras 1, 2 y 3 ).

Hace casi cuarenta años que Heinrich Beriin publicó la documentación relativa al retablo mayor de Meztitlán, junto con otros documentos que enriquecen la información respecto al autor de dicha obra: Salvador de Ocampo. ${ }^{16}$ En años más recientes José Vergara Vergara localizó en el Archivo de Notarías de la ciudad de México otro documento relacionado con uno de los retablos laterales del mismo conjunto. Este mismo investigador halló otro documento acerca de un retablo que ornaba la capilla doméstica de la Hacienda de San Felipe, en la jurisdicción de Mixquiaguala. ${ }^{17}$ Véase el Apéndice de este artículo.

Con base en la documentación publicada por Berlin, emprendimos un primer análisis formal e iconográfico del retablo mayor de Meztitlán. Y aunque a dicho estudio remitimos al lector interesado, dada la finalidad del trabajo que ahora presentamos, hemos de resumirlo aquí ${ }^{18}$ (figura 4 ).

Tal como señalamos líneas arriba, su autor fue Salvador de Ocampo, insigne artífice que trabajó en México durante el último tercio del siglo XVII. El retablo fue encargado por el gobernador, alcalde y maestro de capilla de dicho pueblo, en nombre de los naturales. El contrato se celebró en la ciudad de México entre tales autoridades y Salvador de Ocampo (maestro de ensamblador), Nicolás Rodríguez Juárez (maestro de pintor), José de Gaona Sarmiento (maestro de batihoja) y Francisco Sánchez (maestro de dorador). La obra debía entregarse en el lapso de un año y costó 6800 pesos de oro común. De la cantidad pagada, Nicolás Rodríguez Juárez, autor de las pinturas, recibiría 200 pesos.

\footnotetext{
16 Heinrich Berlin, "Salvador de Ocampo. A Mexican Sculptor". The Americas, v. IV, n. 4, pp. 415.428, Washington, D.C., 1948.

${ }^{17}$ Comunicación personal al autor en 1977. Agtadezco al señor José Vergata Vetgata la copia que me facilitó de ambos documentos.

13 José Guadalupe Victoria, op cit.
} 
Lo primero que salta a la vista en este retablo es el gran movimiento de su planta. No resulta exagerado decir que su alzado adopta la forma de biombo.

De gran altura, la obra descansa sobre un basamento de madera y consta de un banco, tres cuerpos y un remate; en sentido vertical se distinguen cinco calles. La del centro está ocupada básicamente por relieves; las calles intermedias son de menor anchura y alojan esculturas. En las de los extremos destacan seis grandes pinturas. En el banco, para marcar los ejes verticales del retablo, hay angelillos atlantes.

E1 tipo de columnas utilizadas en este retablo es salomónico, rematadas todas por capiteles corintios; sin embargo, las del primer cuerpo sólo presentan senos y gargantas en tres de sus tercios. En los extremos laterales del tercer registro no hay columnas. Todas ellas están decoradas con motivos vegetales, sobre todo guías de parra y racimos de vid (figura 5).

En los registros inferiores son notables los entablamentos que tienen el mismo movimiento de la planta y cuyas cornisas se proyectan especialmente sobre los resaltos de columnas. El escultor entiqueció dichas cornisas con pinjantes en gracioso ritmo geométrico, así como con roleos que se desplazan a manera de gigantescas claves sobre los marcos de los relieves y de los lienzos. Precisamente en la calle central del primer registro se forma una especie de frontón roto cuyos extremos se vuelven sobre sí mismos a manera de roleos.

En el tercer registro, la cornisa queda reducida a las calles intermedias y la del centro presenta las mismas características que las del registro bajo.

La ornamentación del retablo se completa con una orla abundante en hojarasca que flanquea los dos primeros registros para continuar de manera más vigorosa en el tercero y en el remate.

Por lo que respecta a las pinturas, son las que realizó Nicolás Rodríguez Juárez y representan pasajes de la vida de la Virgen y de Jesucristo. Su orden es el siguiente: Adoración de los Pastores, La Circunsición, La Ascensión, Nacimiento de la Virgen, Presentación de la Virgen al templo y La Asunción.

La parte central del primer cuerpo ha sufrido una seria modificación. En lugar de las esculturas originales se ha colocado una imagen de la Inmaculada Concepción, pintura antigua - con marco poco agradable-, sin duda, pero llevada de otro sitio y venerada bajo la advocación de Nuestra Señora del Refugio.

En cuanto a las esculturas, se conservan las siguientes: Santo Tomás de Villanueva, San Juan de Sahagún y San Guillermo de Aquitania, San Nicolás de Tolentino, Santa Mónica y Santa Clara de Montefalco; todas 
sobre suntuosas peanas. Los relieves se encuentran distribuidos de la siguiente manera: en el banco están los bustos de los cuatro evangelistas: San Lucas, San Juan, San Mateo y San Marcos; además de San Bernardo y San Benito. En la calle central y de abajo hacia arriba se aprecian: $L a$ Adoración de los Reyes, El Calvario y el Padre Eterno, acompañado por dos figuras que posiblemente aluden a dos virtudes: Fe y Esperanza (figuras 6 y 7 ).

\section{Retablos del siglo XVIII}

Los ejemplos que datan de esa centuria constituyen el más alto porcentaje de la retablística conservada en la entidad. Hasta el momento presente son pocos los documentos localizados referentes a obras de dicha centuria; salvo los dos conocidos respecto a los retablos laterales de Meztitlán, obras que hemos considerado como pertenecientes al siglo XVII, dado el tipo de apoyo que presentan, o sea columnas salomónicas.

Según hemos podido constatar, otro tipo de apoyo ampliamente utilizado fue la pilastra estípite, siendo el ejemplo más notable el retablo mayor de Apam; aunque también hay otros conjuntos significativos como el de Santa María Nativitas (Cuauhtepec) y el de Nuestra Señora del Carmen en Ixmiquilpan.

Otro tipo de apoyo identificado es la llamada pilastra-nicho tal como puede apreciarse en el retablo mayor de Atotonilco de Tula (figura 8).

A los retablos con pilastras nicho suceden aquellos de tipo anástilo; es decir se trata de estructuras carentes de apoyo y en las que predomina la planimetría. Aunque hay casos en que ese tipo de estructuras todavía conservan estípites, según puede verse en los retablos laterales de la parroquia de Huichapan.

\section{Retablos neoclásicos}

Un último grupo de retablos lo constituyen aquellas obras que la historiografía del arte novohispano denomina neoclásicas; obras muy difíciles de ubicar cronológicamente. En algunas de ellas se utilizaron pinturas de la época barroca; así lo hemos constatado en un retablo conservado en la iglesia de Meztitlán, donde varios lienzos de la vida de la Virgen se integraron a una estructura neoclásica. 


\section{Conclusión}

Es muy difícil, por el momento, tratar de postular cualquier conclusión respecto a los retablos conservados en el estado de Hidalgo. Sin embargo, a nadie escapa que ninguna de esas obras puede desligarse de la producción retablística novohispana de los tres siglos. Tanto en la estructura general como en los detalles se advierten los mismos patrones. Otro tanto puede decirse de la iconografía y del patronazgo de las obras. Y no tenía por qué darse tanta diferencia, pensamos, pues tal como señaló hace varios años Elisa Vargas Lugo, la cercanía de los territorios que hoy conocemos como Estado de Hidalgo, respecto a la ciudad de México, redundó en que la población española prefiriera vivir en la capital y trasladarse solo temporalmente a esas regiones para vigilar sus propiedades agrícclas o mineras, esencialmente. Lo que redundó en un intenso comercio entre las distintas poblaciones y la capital; dicho comercio incluía, por supuesto, las obras artísticas y en un renglón principal los retablos.

Así, tratar de encontrar una "escuela" o "foco artístico" en el Estado de Hidalgo nos parece inútil. Las obras conservadas más bien aparecen emparentadas con las que se conservan en la capital del virreinato. De hecho, a artistas muy renombrados como Salvador de Ocampo, Francisco Martínez y José de Sayagos les fueron encomendadas obras para sitios muy lejanos como Meztitlán. Pero la lejanía no era un obstáculo para que los artifices desdeñaran cualquier encargo; al contrario, era una manera de mantener la producción de sus talleres.

Como quiera que sea, estas suposiciones sólo podrán ser confirmadas - rechazadas en el momento en que contemos con el Catálogo de Retablos Novohispanos en el Estado de Hidalgo; el cual ojalá pronto logremos concluir. 


\section{A PE NDI C E}

Concierto pa vn Sepasse por esta carta como yo Joseph Saiago maestro Corateral. de ensanblador vezino desta ciudad de Mexico digo que por quanto estoy conbenido y consertado con Phelipe dias de espinossa vezino y labrador de la jurisdicción de misquiaguala y el capitan Joseph hurtado de mendoça vez ${ }^{\circ}$ desta ciudad en su nombre en hazerle vn colateral de madera de ayacaguite buena y seca que ha de tener de alto siete Varas y dos tersias y de ancho seis varas, y su soclo para la capilla de la hazienda del suso dcho con tres cuerpos de alto y tres calles de ancho dorado de oro limpio y jaspeado y con la pintura que expresan las condiciones que exivo firmadas de mi nombre y segun el modelo y planta de dho corateral que he de dar acabado en el tiempo que en ellas se declara y me ha pedido el dho capitan Joseph hurtado en dho nombre que otorgue la escriptura de obligasion confianza necesaria y lo he tenido a bien y poniendolo en efecto y reduziendo lo referido a contrato publico otorgo que me obligo de hazer y acabar dho corateral para la dha capilla de la hazienda del dho Phelipe dias de espinossa del tamaño ancho pintura forma y manera que expresan dhas condiciones y dorado y armado que exivo para que el presente escribano las ponga en su Registro y saque por principio del traslado que desta diere dentro de siete meses que corren y se quentan desde oy dia de la fha desta en adelante armado y acabado en toda forma y arte y a satisfación de los susodhos y del maestro que señalaren y por precio de vn mill pessos de oro comun que se me an de pagar doscientos pesos para començar dha obra, y veinte pesos cada semana, doscientos pesos encomensandose a dorar y la Resta a el fin de acabada dha obra puesta y armada en su capilla a satisfacion de los susodhos y por defecto de no serio o no acabarla con toda perfecion al dho plaço plaço (sic) puedan los susodhos o quien fuere parte legitima por el dho Phelipe dias mandarlo a hazer a otro maestro y por lo mas que le costare y hubiere descuido se me pueda executar como por deuda liquidada y de plaço cumplido y por las costos y salarios del cobrador diferido en el juramento del suso dcho sin otra prueva ni averiguasion de que les Relevo, y para que así lo cumpliere doi por mi fiador a D. Joseph de torres dueño de caxon de erraje en la plaça mayor desta ciud y vezo della el qual estando presente otorgo en la mas vastante forma que puedo que fio al dho Joseph saiago en tal manera que el susodho hara y acabara dha obra segun y como se expresa en sus condisiones dorado y armado al plaço y tiempo Referido con toda perfeccion y arte dondeno (sic) yo como su fiador 
y prinçipal pagador haziendo como hago de deuda y causa agena mia propia y sin que contra dho prinçipal ni sus vienes se haga diligencia ni execussion de fuero ni de derecho cuyo veneficio renuncio bolbiere y pagare la cantidad de pesos que el suso dho hubiere reseuido por quenta de dho corateral y no siendo de satisfacion y conforme a arte lo mas que costare haziendo otro maestro y las costas.

Memoria de las condiciones tamaño forma y manera que ha de tener y ser vn corateral que yo Joseph saiago vezino desta Ciud me obligo a hazer como maestro de ensamblador y dorador de oro limpio para la capilla de la hazienda de Phelipe dias de espinossa en la jurisdicion de mizquiaguala por mano del capn Joseph hurtado

- Primeramente ha de lleuar vn soclo todo Resalteado con suboselon y acornisado los Restante y a de ir dorado todo lo que fuere molduras y lo demas jaspeado y de madera de ayacaguite como todo lo demas de dho corateral

Ensima de dho soclo su banco con seis masicos y en cada vno su nicho de escultura y entre masiso y masiso dos lienços de la vida de san Diego como todos los demas y enmedio su sagrario con sus dos colunitas y en la puerta pintado lo que fuere del gusto del dueño con sus corteças en los medios

- Encima de dho vanco que toca al primer cuerpo ha de lleuar seis colunas salomonicas todas talladas con sus seis pilastras detras dellas; a los lados sus dos entrecalles con sus molduras talladas donde ban otros dos lienços de pinturas; en el medio vna caja capialsada con sus molduras en contorno y su Repissa y bolantes alrededor todos de talla calado y dha repissa tallada

Ensima de dhas colunas su cornisa con seis masiços; en la calle de enmedio ha de yr en punto Redondo y en los otros dos lados sus corteças y enmedio vna sotabanca que toca a el primer cuerpo; ensima de tha sotabanca otras seis colunas que componen al segundo cuerpo diferentes de las de abajo de talla y obra también con sus seis pilastras detras de ellas; a los dos lados otros dos lienços de pintura de dha vida de san Diego con sus quadros todos tallados; y en el medio otro lienço de san felipe apostol con su quadro todo tallado y sus corteças; ensima de dhas colunas su cornisa con sus seis maçisos y todas sus molduras talladas; ensima su sotabanca que toca a el tercer cuerpo; el qual ha de lleuar en el medio vn lienço de santa Beatris con su quadro tallado con sus corteças a los lados, dos motilos en cada lado que an de yr mui 
bien tallados; los quales an de cargar una cornisa de medio punto con sus quatro maçisos, y ensima el espíritu santo en su mundo conque remata la calle de enmedio

A los lados otros dos lienços con sus quadros tallados y a los dos lados sus motilos que carguen su cornisa, y ensima su tarja que Remate dhos lados con sus argotantes que quisiere las partes del punto de la dha capilla, en los dos cuerpos de abajo sus guardapoluos el qual dho corateral ha de lleuar tres cuerpos de alto y tres calles de ancho que el alto de dha obra ha de ser de siete baras y dos terçias y de ancho seis varas cabales

Toda la cual dha obra ha de yr dorada de oro limpio el soclo como esta referido en su condicion, dhas pilastras las faxas doradas y los coxines jaspeados que son las que an de yr detras de las colunas y los lienços de dho corateral que son once con la puerta del sagrario an de ser mui al olio de la vida de san Diego san Phelipe y santa Beatris y el sagrario que lo que se me ordenare, todo lo cual me obligo a hazer y acabar dentro de siete meses que corren desde hoy a satisfasion del capitan Joseph hurtado y de la persona que señalare acabado y dorado en toda forma - -

- $\mathrm{y}$ es condision que el dho capitan Joseph hurtado ha de embiar la gente necessaria para que lleve toda la dha obra con una persona de razon que entienda su ydioma, y yo he de yr con ellos para que no se maltrate y yrlo armando

y assimismo es condision que el precio y cantidad en que nos ajustaremos se me ha de yr dando en esta manera, doscientos pesos para començar dha obra; y veinte pesos cada semana, y doscientos en comensandose a dorar y lo restante a el fin de dha obra acabada y puesta que sea en dha capilla al gusto de dho capitan de lo cual hemos de otorgar escriptura dando fiador suficiente fho en mexico a veinte de diziembre de mill seiscientos y ochenta y quatro años y lo firmamos de nuestros nombres -

Joseph Sayago

(firma) 